\title{
Erratum to: X-ray Induced and Thermostimulated Luminescence of new Fluorine Containing Compounds (Potential Luminophores, Scintillators and Dosimeters)
}

\author{
Nina N. Boroznovskaya ${ }^{1}$ - Maria M. Godneva ${ }^{2}$ - Alexandra P. Korneva ${ }^{1}$. $^{-}$ \\ Anton V. Klimkin ${ }^{3}$
}

Published online: 31 May 2017

(C) Springer Science+Business Media New York 2017

\section{Erratum to: J Fluoresc}

DOI 10.1007/s10895-016-2001-2

The original article was corrected. The corrected parts are as follows:

Section "Results and Discussion", first paragraph, 4th sentence should read:

The first three types are attached to fluoric compounds (radiation within ultraviolet range is predominant), the others are typical for fluorosulphatic (curves VI, VII at Fig. 1) and fluorophosphatic (curves IV, V at Fig. 1) compounds which radiate scarcely in whole optical range of wave lengths.

Subsection "Sodium Fluorooxalates Luminescence" should read "Potassium Fluorooxalates Luminescence"

Subsection "Potassium Fluorooxalates Luminescence", 2nd and 3rd paragraphs should read:

According to IR spectra $\mathrm{K}_{2} \mathrm{ZrF}_{4} \mathrm{C}_{2} \mathrm{O}_{4} \cdot 2 \mathrm{H}_{2} \mathrm{O}$ contains two types of oxalate groups, bridge bonds (through oxygen and

The online version of the original article can be found at http://dx.doi. org/10.1007/s10895-016-2001-2

Nina N. Boroznovskaya

boroznovskaya@mail.ru

National Research Tomsk State University, 36, Lenina prospekt, Tomsk 634050, Russia

2 Institute of Chemistry and Technology of Rare Elements and Mineral Raw Materials of the Kola Science Center, RAS, Apatity, Russia

3 Institute of Atmosphere Optics SD, RAS, 1, Zueva sq, Tomsk 634021, Russia zirconium atoms); fluorine atoms are end ligands. Although fluorine the substitution with $\mathrm{C}_{2} \mathrm{O}_{4}{ }^{2-}$ originally decrease XRL intensity (in comparison with $\mathrm{K}_{2} \mathrm{ZrF}_{6}$ ), after heating and dehydrating intensity increases to $\mathrm{K}_{2} \mathrm{ZrF}_{6}$ level.

$\mathrm{KZrF}_{3} \mathrm{C}_{2} \mathrm{O}_{4} \cdot 3 \mathrm{H}_{2} \mathrm{O}$ turned out to be the most perspective compound, especially after slight heating to $100-130{ }^{\circ} \mathrm{C}$. Further heating leads to insignificant decrease of XRL intensity (Fig. 4).

Section "Acknowledgements", last line should read: Project \#2282.

Figure 2 was incorrect. The correct figure is shown below.

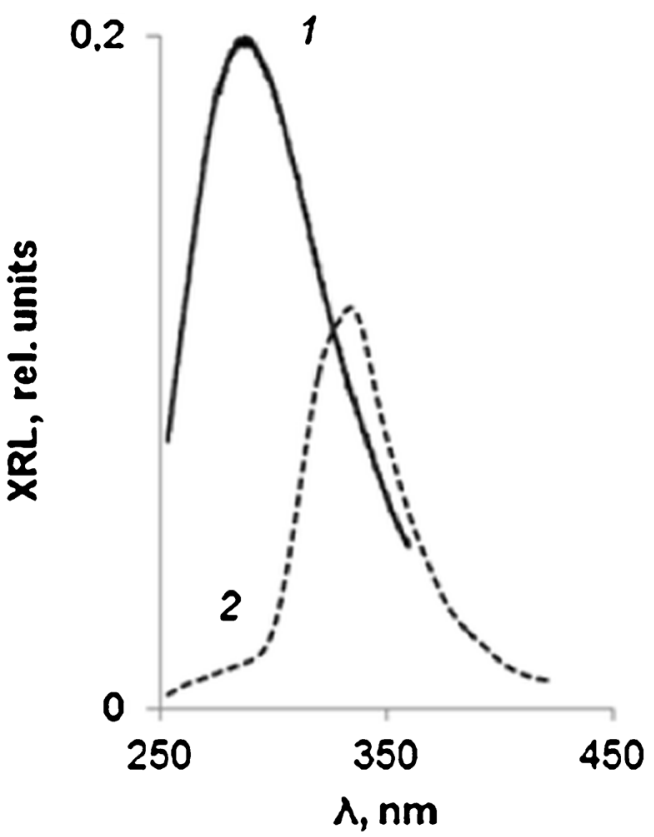

Fig. 2 XRL spectra of $\mathrm{CaF}_{2}(1)$ and $\mathrm{LiF}(2)$ 